\title{
O TRABALHO DOS PROFESSORES NA ESCOLA: QUANDO O TEMPO SE TRAI.
}

\author{
Liliana Soares Ferreira \\ Professora do Programa de Pós-graduação em Educação \\ Universidade Federal de Santa Maria / UFSM \\ anaililferreira@yahoo.com.br
}

\section{RESUMO}

O trabalho dos professores é, imerso em condições políticas e sociais que lhe exigem agir, planejar, avaliar a produção do conhecimento sua e dos estudantes e, para tanto, o tempo é fundamental: para conhecer, para se conhecer, para expor saberes, refletir e elaborar linguagens sobre esses saberes, sistematizá-los, tornando-os conhecimento. O tempo de produzir conhecimento é a própria produção desse conhecimento, senão, esse trabalho ou fica prejudicado, ou se torna um não-trabalho, ou se consome sob a forma de cumprimento de um emprego. É nesse sentido que afirmo que o tempo se trai: por não cumprir o seu sentido de ser. Com certeza, há outras explicações, porém, ater-me-ei, a seguir, a essas três possibilidades, entendendo que, através dessa discussão, se pode apresentar uma abordagem do trabalho dos professores necessária e propícia para re-encaminhamentos de outros estudos.

Palavras-chave: trabalho, não-trabalho, emprego, tempo, escola.

\section{THE WORK OF THE TEACHERS IN THE SCHOOL: WHEN TIME IF BETRAY.}

\begin{abstract}
ABSCTRAT
The work of the teachers is, immersed in conditions politics and social that they demand to it to act, to plan, to evaluate, the production of the knowledge its and the students and, for in such a way, the time is basic: to know, to know themselves, to display to know, to reflect and to elaborate languages on these to know, systemize them, becoming them knowledge. The time to produce knowledge is the proper production of this knowledge, of the opposite, this work or is wronged, or if it becomes a not-work, or if it consumes under the form of fulfilment of a job. With certainty, it has other explanations, however, I will abide myself, to follow, to these three possibilities, understanding that, through this quarrel, if it can present a boarding of the work of the teachers necessary and propitious for reverse speed-encaminhamentos of other studies.
\end{abstract}

keyswords: work, not-work, job, time, school

\section{INTRODUÇÃO}

Entendo que o tempo é uma criação dos seres humanos como um modo de conhecer e dominar o mundo, a si próprio e sua produção, além de permitir a regulação da vida, o controle das ações e dos corpos. Portanto, estou partindo do suposto que essa categoria é basilar no entendimento dos seres humanos, como se organizam, como produzem, como vivem, como trabalham, acumulam e fazem circular riquezas. 
Embora seja um aspecto significativo para que se possa melhor conhecer os seres humanos, o tempo é um dos aspectos menos estudados quando se discute o trabalho dos professores, este tema ao qual me dedico a estudar. E mais, entre as várias abordagens desse tema relativo ao trabalho desses profissionais, penso que vale a pena refletir sobre o que estou denominando tempo que se trai, referindo-me ao fato dessa criação humana, em muitas situações, não cumprir sua razão de ser que é permitir e possibilitar que os sujeitos trabalhem efetivamente. Trair no sentido de corromper o seu sentido de ser: se o tempo é uma criação humana, na medida em que não atende ao objetivo pelo qual é criado, trai sua razão de ser e, em decorrência, trai seu criador. É o que pretendo argumentar a seguir.

Esclareço, ainda, que o trabalho dos professores, pedagógico por excelência ${ }^{\mathrm{i}}$, é a produção do conhecimento ${ }^{\text {ii }}$ sua e dos estudantes, em momentos sociais denominados aula e, para tanto, o tempo é fundamental: para conhecer, para se conhecer, para expor saberes, refletir e elaborar linguagens sobre esses saberes, sistematizá-los sob a forma de conhecimento. Porém, conhecer é uma ação particular de cada ser humano e, por isso, não pode ser tratada genericamente. Ou, em outras palavras: como se pode prever o tempo exato necessário ao conhecer? Cada ser humano tem características diferenciadas e exige mais ou menos tempo para produzir conhecimento: "O tempo dedicado ao conhecimento é objetivamente aberto e contíguo, não se pode marcar horário para ele acontecer [...]". (BEZERRA; SILVA, 2006, p. 6) Por esse motivo, o tempo de produzir conhecimento é a própria produção desse conhecimento. Quando não há essa condição, esse trabalho ou fica prejudicado, ou se torna um não-trabalho ${ }^{\text {iii }}$, ou se consome sob a forma de cumprimento de um emprego. Com certeza, há outras explicações, porém, ater-me-ei, a seguir, a essas três possibilidades, entendendo que, através dessa discussão, se pode apresentar uma abordagem do trabalho dos professores necessária e propícia para re-encaminhamentos dos estudos que se vem realizando.

\section{O tempo e o trabalho dos professores}

A noção do tempo não é homogêna, é cultural, difere conforme a formação social, uma vez que está imersa na vida das comunidades. Como explica Gourevitch:

Cada civilização percebe o tempo através de sistemas que lhes são próprios. Estes se formam durante a atividade prática dos homens, à base de sua própria experiência e da tradição herdada das gerações anteriores. A cada etapa do desenvolvimento da produção, da evolução da economia e do homem com relação ao meio natural, correspondem maneiras particulares de viver o mundo. (1975, p. 263)

Por exemplo, em uma cultura popular, no interior do Brasil, o tempo, assume, segundo Bosi, características bem específicas: “[...] é cíclico. [...] o seu fundamento é o retorno de situações e atos que a memória grupal reforça atribuindo-lhe valor" (BOSI, 1987, p. 11). Portanto, o tempo é uma criação humana para responder ao desejo de explicar-se e de explicar o mundo e é, também, fator de controle dos corpos e dos seres a serviço do capital.

Esses elementos já bastariam para explicar aplicações da categoria tempo nesse artigo. Entretanto, nem sempre foi assim. Cabe buscar referências que ajudem a compreender como essa categoria se tornou tão relevante na discussão sobre o trabalho humano.

O tempo surge como categoria já para os povos primitivos, cujos rituais e mitos ${ }^{\text {iv }}$ marcavam a diferenciação temporal, as passagens das épocas e acabavam por registrar a 
própria história daquele grupo. Bem antes do calendário, já era possível dimensionar a passagem de uma época a outra, através dos ritos comunitários como o plantio, os movimentos do grupo, e as narrativas ${ }^{v}$, registrando uma repetição, cuja circularidade contém, em si, o movimento. Assim, para os grupos humanos antigos "[...] o tempo não se desenrola de maneira linear: do passado para o futuro, mas ora é imóvel, ora é cíclico". (GOUREVITCH, 1975, p. 263) Os fatos parecem se repetir periodicamente: "Aquilo que já foi, retorna a intervalos determinados”. (GOUREVITCH, 1975, p. 263) Tal concepção de tempo, “[...] está em grande parte ligada ao fato de que o homem não se desligou da natureza, e sua consciência se subordinou às transformações periódicas das estações do ano e dos ciclos de produção que lhe são adaptados" (GOUREVITCH, 1975, p. 265). Devido a esse jeito humano de compreender e estar submetido ao tempo, a interpretação dos fatos e do mundo também passou a ocorrer em acordo com "categorias míticas" e tal procedimento gerou "[...] a crença do eterno retorno". (GOUREVITCH, 1975, p. 263) Ao buscar-se entender essa relação humana com o tempo, destaca-se a circularidade, que também garante e alimenta a memória, permitindo a impressão que o tempo e, portanto, os fenômenos e o mundo vão sendo dominados pelos seres humanos, que se vêem, assim, poderosos. Chauí explica que a circularidade era entendida como "[...] a repetição eterna [...] medida de tudo quanto é perecível" (2000, 71), embora seja "linear e finito", e destaca: "Enquanto o tempo cíclico exclui a idéia de história como aparição do novo, pois não faz senão repetir-se, o tempo linear dos entes da Natureza introduz a noção de história como memória". (CHAUÍ, 2000, p. 71) Nesse contexto, a criação de um modelo de calendário necessário à organização do plantio e da colheita é a expressão de um ilusório domínio do tempo.

A cultura greco-latina, dicotomicamente, revisou essa noção de tempo, opondo-se e valorizando-a. Opondo-se, ao determinar existir um tempo cronológico e um de fruição $\left(\right.$ Kronos e Kairós ${ }^{\mathrm{vi}}$ ). Valorizando-a, na medida em que, através dos mitos, mostra o herói como valoroso, sobrehumano e recriador do mundo. Por isso, revela um tempo: "[...] épico, narrando os grandes feitos de homens e cidades cuja duração é finita e cuja preservação é a comemoração" (CHAUÍ, 2000, p. 72). Com Platão, o tempo passa a ser indissociado do universo: "[...] o tempo não existe por direito próprio, sendo uma característica do universo" (WITROW, 1993, p. 57), estando em movimento contínuo. Aristóteles, mais tarde, refutou essa premissa e estabeleceu uma relação entre tempo e mudança, supondo que o movimento pode cessar, mas o tempo não cessa (WITROW, 1993, p. 57). Aristóteles indagava-se sobre quais eram as marcas do anterior e do posterior, mas não tinha respostas. Interrogava-se se as marcas estariam a critério da alma humana, ou dos próprios seres humanos, de certa maneira, responsáveis "[...] pela existência da irreversibilidade do mundo, o que muitos físicos ainda hoje pensam". (PRIGOGINE, 2008, p. 65)

$\mathrm{Na}$ Idade Média, a temporalidade deixa de equivaler-se a movimento e passa a ser controlado como o tempo da vida dos seres humanos, regulado pelo badalo dos sinos nas catedrais. Essa forma de lidar com a temporalidade denota uma indissociação da Natureza e uma associação humana com a vontade de Deus: “[...] o tempo judaico é expressão da vontade divina que o submete a um plano cujos instrumentos de realização são os homens afastando-se Dele e Dele se reaproximando por obra Sua”. (CHAUÍ, 2000, p. 72) Trata-se, ainda, segundo Whitrow (1993, p. 24), da dimensão temporal mais linear até então, menos apegada a compreensões cíclicas e pautada na crença de que os acontecimentos não se repetem. Paulatinamente, este tempo do sagrado, orientado pela Igreja, vai se contrapondo ao tempo profano, dos mercados, dos burgueses em ascensão:

Da mesma forma que o camponês, o mercador está submetido, na sua 
actividade profissional, em primeiro lugar ao tempo meteorológico, ao ciclo das estações, à imprevisibilidade das intempéries e dos cataclismos naturais. Neste aspecto, e durante muito tempo, ele só necessitou de submissão à ordem da natureza e de Deus e só teve como meio de acção, a oração e as práticas supersticiosas. Mas quando se organiza uma rede comercial, o tempo torna-se objeto de medida. (LE GOFF, 1979, p. 51)

Também a modernidade, recuperando a tradição greco-latina, cultivou a noção do herói, cujos feitos se mantêm apesar da passagem dos anos. Essa noção, então, é integrante da cultura na época, porém, perdeu sua vinculação natural ao pensamento greco-latino clássico, alterando-se com a influência do pensamento católico na Idade Média. Tais ponderações são significativas se for considerado que as noções culturais nas sociedades ocidentais elaboram-se sob influência do pensamento greco-latino e judaico-cristão. Sobre esta distribuição do tempo na Idade Média, Laner afirma: "Com o último dia da semana dedicado ao Criador, a Igreja gerou os pressupostos necessários para poder controlar o tempo econômico e social" (2005, p. 15). Por esses motivos, passou a haver uma particular relação entre os seres humanos medievais e o tempo, diferenciada da contemporânea, pois, até então, idades e horários exatos não eram prioridade e o tempo humano estava "[...] subordinado pela dimensão do tempo eclesiástico, ritmado pelas funções religiosas, festas litúrgicas e, ainda, marcado pelo quotidiano feudal, em que as guerras eram constantes". (LANER, 2005, p. 17).

Embalada pela ascensão burguesa e pelo advento da fábrica, a Modernidade utiliza a noção de tempo para regular a produção, criando diferenças na relação de cada sujeito, conforme seu lugar social, com a passagem temporal.

Nessa maneira de conceber, o controle do tempo está incluso entre as diversas modalidades de controle da vida dos seres humanos. Para que assim seja, antes, é necessário controlar a organização do tempo, para controlar o próprio tempo, entendendose a organização como arbitrária e submetida a poderes. Veja-se, por exemplo, a organização da semana de trabalho. Atualmente, são vividos dois modelos de disposição do tempo semanal de trabalho, prioritariamente: dois mais cinco e um mais seis. O último é oriundo da Idade Média, estabelecido sob a perspectiva da Igreja, reportando-se ao início do texto bíblico que relata a gênese do mundo, afirmando que Deus teria trabalhado seis dias e descansado no sétimo para contemplar sua criação. (LANER, 2005, p. 15) Porém, para contar as horas diárias, foi mantida a tradição romana, e estabelecido o rigor dos badalos dos sinos nas igrejas para: "[...] impor o seu ritmo e seu significado ao tempo de todos os indivíduos, fossem monges, nobres ou agricultores" (LANER, 2005, p. 15). Esse tempo acaba por regular a vida e o trabalho e, ao considerar o tempo como dimensionador do trabalho, é possível contar com a explicação de Thompson relativa ao tempo ser medido, em muitas culturas, por contextos denominados "obrigações da profissão" (1991, p. 48). O autor explica que estas obrigações se pautavam pela compreensibilidade, uma vez que pertenciam ao cotidiano, aproximando a vida e o trabalho, superando o tempo demarcado pelo relógio que mecaniza o fazer (THOMPSON, 1991, p. 48).

Chega-se, então, à cotidianidade, dimensão do tempo resultante da aceleração do desenvolvimento dos modos de produção acabou por suplantar esses costumes, exigindo controles mecânicos mais efetivos e de ordem coletiva. Assim, a aceleração do processo de urbanização a partir da Idade Moderna gerou novas modalidades de controle do tempo, com a substituição das torres da Igreja pelas torres que marcavam os horários de trabalho. Foi assim que se estabeleceu a concepção do tempo na atualidade, com base no uso do relógio, impulsionado pela expansão do uso de "[...] torres de relógio mecânico do século XIV e com o surgimento do relógio individual, que reflete uma dimensão de tempo 
individual" (LANER, 2005, p. 19). Essa evolução tecnológica do relógio estabelece também "[...] uma dependência do tempo privado para com o público, consequiência da promoção ideológica do trabalho" (LANER, 2005, p. 19). A complexificação das relações de trabalho alterou esta rotina:

Os que estão empregados experimentam a distinção entre o tempo do patrão e o seu "próprio" tempo. E o empresário tem de utilizar o tempo dos seus empregados, tem de fazer com que ele não seja desperdiçado. Já não se trata de uma tarefa, o que pontifica é o valor do tempo reduzido a dinheiro. O tempo torna-se dinheiro - não passa, gasta-se. (THOMPSON, 1991, p. 49)

O relógio tornou-se peça de prestígio e distinção de poder: "Sempre que um grupo de trabalhadores conseguia melhorar o seu nível de vida, a aquisição do relógio era uma das primeiras coisas a serem notadas pelos visitantes" (THOMPSON, 1991, p. 56). Como a caneta, o relógio assume o lugar de elemento fetichizado: representa poder. Quem tem um relógio, aparentemente, controla o tempo. Quem carregava uma caneta, nas culturas populares, até bem pouco tempo, aparentava ter o conhecimento consigo. Com o relógio, "o tempo contado passa a ser um curso temporal objetivo, contínuo, uniforme e infinito" (NUNES, 1992, p. 134). Estabeleceu-se uma distinção objetivada entre passado, presente e futuro, uma transição visível, materializada do tempo. Também na escola o relógio passou a ser interveniente no trabalho dos professores, porque perpetuava "[...] a cronometria apreendida durante a infância na vida da comunidade, e constitui, assim, num símbolo cultural e num mecanismo de controle social da duração. [...]". (ESCOLANO, 1998, p. 4445). Por esses motivos, o adentramento concreto da escola no mundo da produção fabril, pode ser metaforizado com a introdução do relógio dessas instituições, com "[...] claro significado cultural, uma clara função pedagógica que se acrescenta às intenções educadoras das estruturas espaciais das instituições". (ESCOLANO, 1998, p. 44-45)

A relação entre produção, lugar social e tempo se complexificou ainda mais com o advento da industrialização, quando [...] apareceu a necessidade de uma rigorosa medição do tempo, porque na indústria têxtil convém que a maioria dos operários [...] vá e venha para o trabalho, a horas fixas". . (LE GOFF, 1979, p. 52) Iniciou-se, então, uma rígida organização do trabalho, que Le Goff denominou "prenúncio longínquo do taylorismo" $(1979$, p. 52), fazendo com que o tempo começasse a se racionalizar e laicizar. (LE GOFF, 1979 , p. 52). Marx assim se referiu a essa época, destacando a ampliação da jornada de trabalho e o aproveitamento da força de trabalho de pessoas independentemente do gênero ou faixa etária:

O Capital levou séculos, antes de surgir a indústria moderna, para prolongar a jornada de trabalho até seu limite máximo normal e, ultrapassando-o, até o limite do dia natural de 12 horas. A partir do nascimento da indústria moderna, no último terço do século XVIII, essa tendência transformou-se num processo que se desencadeou desmesurado e violento como uma avalanche. Todas as fronteiras estabelecidas pela moral e pela natureza, pela idade ou pelo sexo, pelo dia e pela noite foram destruídas. (MARX, 2008, p. 320)

Até agora, viu-se como tem sido elaborada a categoria tempo pelos seres humanos: para os povos da Antigüidade, um tempo mítico, circular, revelador da necessidade de 
manter vivas as tradições; os povos greco-latinos relacionavam tempo, universo e movimento, desdobrando-o entre a cronologia e a fruição; para os seres humanos na Idade Média, o tempo divino, que controla a vida dos seres humanos com base na lei de Deus; a modernidade inaugura o tempo da produção, do trabalho, da razão. Essas evoluções no esclarecimento da categoria tempo na modernidade podem ser rastreadas na obra de alguns teóricos significativos dessas épocas. Com base em Noronha, 2003, sintetizam-se essas contribuições: a) para Kant (1724-1804), “[...] o tempo está determinado pelo espaço e a ele subordinado". (NORONHA, 2003, p. 1415); b) para Leibniz, "[...] o tempo é uma ordem de sucessões que fluem de modo uniforme" (NORONHA, 2003, p. 1415); c) para Hegel (1770-1831), "[...] a razão não estaria no tempo, ela é o próprio tempo" (NORONHA, 2003, p. 1415); d) para Marx (1818-1883) “[...] o tempo histórico é construção de sujeitos históricos em um determinado momento da História efetiva, não se caracterizando, portanto, como algo exterior ao sujeito e à História (NORONHA, 2003, p. 1415). Percebe-se, analisando-se rapidamente essas quatro descrições de pensamento, uma evolução do tempo, na Modernidade, inicialmente, entendido como relativo aos sujeitos individualmente, para um tempo coletivo, produzido social e historicamente, relacionado à produção e ao capital.

Entre os teóricos citados, destaco Marx (2008), que, em O Capital, apresenta uma versão de tempo muito lúcida, descrita por Bensaïd: “[...] uma organização conceitual do tempo como relação social: ciclos e rotações, ritmos e crises, momentos e contratempos estratégicos" (1999, p. 13), que acaba por configurar uma nova representação da História, contrária à racionalidade positivista, ordenadora e classificadora. Com base nestes aspectos, Bensaïd afirma que Marx propôs uma reescrita da História, de modo que esta deixasse de ser sucessão e se tornasse simultaneidade: "Trata-se doravante de levar a história a sério, não mais como abstração religiosa, da qual os indivíduos vivos seriam suas humildes criaturas, mas como desenvolvimento real das relações de conflito" (BENSAÏD, 1999, p. 36).

Na obra de Marx (2008), o tempo aparece como fundamental para se poder mensurar o trabalho. $\mathrm{O}$ estabelecimento de um tempo médio de produção, que o autor denomina ser socialmente necessário, permite o estabelecimento do valor da mercadoria. Há, então, uma interdependência entre a materialização do esforço despendido e o tempo gasto, de tal forma que valorar o primeiro aspecto somente é possível medindo-se o segundo. O que seria um tempo socialmente necessário? Marx responde que se trata do tempo de trabalho: "[...] requerido para produzir-se um valor-de-uso qualquer, nas condições de produção socialmente normais existentes e com o grau social médio de destreza e intensidade do trabalho" (2008, p. 61). Essa maneira de estabelecer um parâmetro de tempo, o social, relaciona-se com o fato de o autor entender o trabalho como uma ação de sujeitos que, coletivamente, produzem e autoproduzem-se, em suas condições de vida humana e material.

O tempo é o campo do desenvolvimento humano. O homem que não dispõe de nenhum tempo livre, cuja vida, afora as interrupções puramente físicas do sono, das refeições etc., está toda ela absorvida pelo seu trabalho para o capitalista, é menos que uma besta de carga. É uma simples máquina, fisicamente destroçada e espiritualmente animalizada, para produzir riqueza alheia. (MARX, 1974, p.98-9)

Nessa perspectiva, o controle do tempo contribui para regular o trabalho. Aumentando ou diminuindo o tempo e mantendo-se ou intensificando-se o ritmo de 
trabalho, poder-se-ia aumentar a produção, gerando mais-valia. Essa lógica simples é um dos movimentos realizados no mundo capitalista. $\mathrm{O}$ tempo parece não ser considerado como espaço médio de produção, mas como algo a ser consumido, ocupado, tangenciado. Tal concepção do tempo controlado é compatível com o capital que não tolera "[...] limitações a seu próprio modo de reprodução sociometabólica" (MẼSZÀROS, 2007, p. 25), portanto, não tolera qualquer menção ao tempo que possa restringir sua expansão, interessando-se tão somente pelo "tempo de trabalho explorável" (MÈSZÀROS, 2007, p. 25), a única dimensão de tempo que suporta. O tempo, sobretudo o tempo histórico, é um fardo para o capital ${ }^{\mathrm{vii}}$ :

[...] talvez a maior acusação contra nossa ordem social dada é que ela degrada o fardo inescapável do tempo histórico significativo - o tempo de vida tanto dos indivíduos como da humanidade - à tirania do imperativo do tempo reificado do capital, sem levar em conta as conseqüências. (MÈSZÀROS, 2007, p. 33)

A contemporaneidade se apropriou dessas elaborações da noção de tempo, propondo a dualidade entre o trabalho como atividade que mortifica o ser humano e o ócio, como real atividade de prazer e fruição. O tempo se amplia em termos de como é concebido, possibilitando à Física contemporânea incluir uma compreensão diferenciada: o espaço-tempo, elaborado a partir da Teoria da Relatividade de Einstein, em 1909 (TASSINARI, 2006). Com isso, foi necessário rever a relação entre a ambientação e a temporalidade.

A teoria da relatividade obriga-nos, contudo, a modificar fundamentalmente as nossas concepções de espaço e tempo. Temos de aceitar que o tempo não está completamente separado nem é independente do espaço, mas sim combinado com ele, para formar um objecto chamado espaço-tempo. (HAWKING, 1994, p. 19)

Tal significação do tempo, agora associada ao espaço, contribuiu para dinamizar as relações sociais e a vida humana de modo geral, tendo como suposto que "[...] quando um corpo se move, ou uma força actua, a curvatura do espaço e do tempo é afectada e, por seu lado, a estrutura do espaço-tempo afecta o movimento dos corpos e a actuação das forças" (HAWKING, 1994, p. 25) Ampliaram-se as potencialiddes de se atribuir sentidos à vida humana, dinamizando ações e percepções, além de interligar os seres entre si e com o universo:

O espaço e o tempo não só afectam como são afectados por tudo o que acontece no Universo. Tal como não podemos falar de acontecimentos no Universo sem as noções de espaço e tempo, também na relatividade geral deixou de ter sentido falar sobre o espaço e o tempo fora dos limites do Universo. (HAWKING, 1994, p. 25)

E mais, o avanço das tecnologias, entre as quais, as que possibilitam a circulação de informações, de comunicação e as relativas à mecanização das ações humanas, exigiu que, devido à informatização, na sociedade contemporânea, lidemos diferentemente com o tempo, pois muda, inclusive, a simultaneidade, que "[...] não é mais apenas a do tempo 
físico, tempo do relógio, mas do tempo social, dos momentos da vida social" (SANTOS, 1994, p. 78). Trata-se de uma realidade, na qual, “[...] as viagens acontecem à velocidade da luz e os espaços são atravessados sem tempo. A distância entre o longe e o aqui torna-se insignificante" (GOERGEN, 2008, p. 12). Um tempo que se expande, estando em todos os ambientes: "[...] é o tempo da metrópole, que transmite a todo o território o tempo do Estado e o tempo das multinacionais e das grandes empresas". (SANTOS, 1994, p. 78) Uma concepção de tempo na contemporaneidade seria "[...] grosseiramente o transcurso, a sucessão dos eventos e sua trama" (SANTOS, 1994, p. 19). O espaço será o ambiente, o meio, "[...] o lugar material da possibilidade dos eventos" (SANTOS, 1994, p. 19). Resulta que o mundo seria a síntese e a soma de tempos e ambientes, e, a todo instante, “[...] mudam juntos o tempo, o espaço e o mundo. De tal modo, nossa grande tarefa é a de apreender e definir o Presente, segundo essa ótica. (SANTOS, 1994, p. 19)

Se esses aspectos foram reveladores de como evoluiu a relação dos seres humanos com o tempo no campo do trabalho, de semelhante maneira têm sido as relações dos professores, esses trabalhadores que lidam com o conhecimento. O trabalho dos professores, por sua especificidade, por lidar com o conhecimento e a linguagem, que não são elementos materializados, tem as condições históricas, culturais, sociais e as contingências dos sujeitos envolvidos, sejam professores, sejam estudantes como intervenientes. Assim, contrariamente ao que se pensa, não é regulando o tempo que se garante haver a produção do conhecimento, mas, ao contrário, investindo na produção do conhecimento se pode alterar o tempo. Portanto, a produção dos professores, o produto final, o conhecimento acontece com uma quantidade de tempo que é variável, subjetiva e em acordo com cada sujeito do processo.

Cabe entender melhor como é possível isso, a partir de dois trabalhos que passo a destacar.

Zarifian (2002), com base em Bergson, apresenta uma interessante diferenciação entre o tempo espacializado e o tempo psicológico e qualitativo. Relativamente ao trabalho, o tempo espacializado acaba por regular, impor rotinas, estabelecer limites. No tempo espacializado encontra-se o que é muito comum ouvir-se haver nas escolas: rotinas. Os estudantes e professores, desde o momento em que entram no prédio, cumprem rituais de rotina. Na Região onde moro, por exemplo, para os estudantes e professores dos anos iniciais do Ensino Fundamental está instituído uma rotina muito interessante e pouco analisada: chega-se à escola, encontram-se os colegas de trabalho na sala de professores, é aguardado o sinal de início das aulas, acompanha-se os estudantes (geralmente em fila) até a sala de aula, inicia-se a aula descrevendo as condições da temperatura, escolhe-se o estudante a ser denominado "ajudante do dia", são avaliadas as tarefas realizadas em casa, faz-se a leitura do dia e seguem-se exercícios ou atividades, somente interrompidas pelo intervalo denominado recreio. Obviamente, essa não é uma descrição de uma seqüência padrão de todas as escolas, mas de uma quantidade significativa delas, revelando, pela repetição, ser um elemento da cultura pedagógica regional. Esse relato revela ser oportuno, muitas vezes, marcar o tempo com a repetição, pois, assim, rotinizado, pode-se acompanhar concretamente a passagem dos minutos, horas. Entretanto, há, nessa escolha, uma perda: da condição de viver intensamente esse tempo, sem precisar apenas se repetir. Quanto mais se insere nessa rotina, menos condições de rompê-la parecem denotar os professores.

Entendo por rotina a repetição mecânica de algo, sabendo que, na verdade, essa é uma convenção, pois não há rotina absoluta. Os seres humanos são demasiadamente criativos para simplesmente se repetirem. O simples fato de, por exemplo, não haver o encontro inicial na sala dos professores, narrado no parágrafo anterior, pode subverter toda 
a sequiência, exigindo um redimensionamento da vivência rotineira e uma re-adaptação dos sujeitos e dos tempos. A escola, nesse viés, seria uma instituição mais criativa, pois sendo composta por sujeitos diferentes, provenientes de culturas diversas, a todo dia, precisa ser revista, repensada, re-articulada. O trabalho dos professores, como efetiva ação pedagógica da escola, jamais seria rotineiro, uma vez que, cotidianamente, precisa ser replanejado, buscando atender a demandas.

Voltando à discussão proposta por Zarifian, diferentemente do tempo espacializado, o tempo psicológico e qualitativo, por sua vez, como mobilização da experiência e estabelecimento de perspectivas, apresenta-se rico em possibilidades, ânimo e torna o trabalho mais humanizado. Nesse sentido, o tempo psicológico é oposto do tempo espacializado. E acrescenta: "O primeiro é o tempo de trabalho; o outro, o tempo do trabalho" (ZARIFIAN, 2002, p. 16).

Em outra perspectiva, Hargreaves (1998) caracteriza os tempos do trabalho dos professores, posto que, reiteradamente, ouvem-se alusões ao tempo ou à falta dele nos discursos destes profissionais: a) o tempo técnico-racional; b) o tempo micropolítico; c) o tempo fenomenológico; d) o tempo sociopolítico. Enquanto os demais referem-se ao tempo que controla, organiza, estipula as características do trabalho e da profissão dos professores, regulando-os em suas iniciativas, o tempo fenomenológico diz respeito ao tempo de cada ser em sua subjetividade e em sua historicidade (HARGREAVES, 1998). Esta abordagem é interessante para que se possa melhor entender e analisar como se organizam as condições de trabalho dos professores, entretanto, não podem ser sobrepostas ao trabalho em si, pois o que se pode analisar é como e em quais condições se produz o trabalho dos professores na escola.

As contribuições de Zarifian, 2002, e Hargreaves, 1998, permitem caracterizar o tempo do trabalho dos professores como fenomenológico, psicológico, embora controlados por lógicas externas relativas a como o capital organiza os aspectos sociais. Então, na escola, não há como desconsiderar que, para seu trabalho, os professores dispõem de um tempo e recebem, em troca, um salário. Seu fazer, a produção do conhecimento, subjetivo, de caráter cultural e simbólico, é complexo e, por que não afirmar, contraditório: sustentado na lógica do mercado, propõe-se a relacionar-se com subjetividades, não materialidades. A contradição exige dos professores discernimento, muitas vezes, não elaborado, pois todo o seu agir é controlado por tempos e espaços: tempo de aula, tempo de reunião, tempo de recreio, sala de aula, sala de reuniões, sala de professores. A relação que esses profissionais estabelecem com o tempo, embora regulada pelos instituídos da escola e do sistema educacional, é fundamental se o objetivo for realizar o trabalho, ou seja, produzir conhecimento, pois esta é uma produção interdependente do tempo: conhecer é praticar o tempo de conhecer, a isso se chama produção, entendida como elaboração, apropriação individual de algo que não se sabia, em um ambiente de linguagem.

\section{Quando o trabalho dos professores fica prejudicado pelo tempo}

A categoria tempo é determinante no agir pedagógico. Primeiro, porque existe uma relação direta entre o tempo dos professores e o do estudante. Se a educação é interativa, quanto mais tempo for utilizado, mais se produz. E, ao contrário, quanto menos tempo se utiliza, diferente pode ser a produção do conhecimento. Segundo, porque todo o controle do trabalho acontece sustentado no tempo que os professores convivem com os estudantes, no tempo que se dedicam ao trabalho pedagógico, no tempo da aula. Tanto é que a escola e o sistema educacional controlam a aula pelo estabelecimento de tempos: quatro horas de aula diária, oitocentas horas de aula no ano. Neste período determinado, medido pelo 
relógio, os profissionais necessitam realizar sua ação, produzir conhecimento com seus estudantes, os quais terão, normalmente, aulas e avaliações, "provar" que aprenderam e "provar" a realização do trabalho pelos professores. Tal controle se insere na perspectiva de controle do tempo de outros trabalhadores, também, reproduzindo as lógicas do capital: "A maioria dos trabalhadores não controla hoje a duração nem a intensidade de seu trabalho" (ENGUITA, 1989, p. 09). Não é possível porque o tempo é também mercadoria na lógica do capital, por isso, "O trabalhador assalariado deve submeter-se aos ritmos impostos pela maquinaria, aos fluxos planificados de produção e às normas de rendimento estabelecidas pela direção" (ENGUITA, 1989, p. 09). Poder-se-ia pensar que, para os trabalhadores que não vivenciam o emprego ${ }^{\text {viii }}$, o tempo seria diferente, mas Enquita, afirma que para quem trabalha por conta própria, há controle também, mas de forma limitada, pois " [...] o movimento dos preços força-o a não se distanciar demasiadamente do calendário, do horário e dor ritmo impostos por aqueles que têm menos escrúpulos em explorar a si mesmos" (ENGUITA, 1989, p. 09).

A relação tempo e trabalho tornou-se mais intensa com o impulso industrial, no início do século XX, e a criação e implementação do modelo taylorista-fordista, alicerçado no rígido controle do tempo para gerar mais produção, muito oportuno no período pósguerra para recuperar a economia, expandiu-se pelas instituições sociais atingindo diretamente a escola. Seus aspectos organizadores foram habilmente aplicados aos tempos escolares, objetivando, assim como na produção fabril: "[...] economia de tempo e o conseqüente acréscimo de rendimento, possíveis de obter pela eliminação de movimentos desnecessários e substituição de movimentos lentos e ineficientes por movimentos rápidos em todos os ofícios [...]. (TAYLOR, 1990, p. 33) Interessante como a orientação de Taylor para as empresas e indústrias acabou por ser entendida como extensiva à escola, movimentando-a em busca dos especialistas que gerenciarão a "atividade produtiva": supervisores, orientadores, administradores:

[...] quase todos os atos dos trabalhadores devem ser precedidos de atividades preparatórias da direção, que habilitam os operários a fazerem seu trabalho mais rápido e melhor do que em qualquer outro caso. E cada homem será instruído diariamente e receberá auxílio cordial de seus superiores, em lugar de ser, se um lado, coagido por seu capataz, ou em situação oposta, entregue à sua própria inspiração. (TAYLOR, 1990, p. 34)

Geraram-se, então, calendários organizados em horas-aulas, que se substituem sofregamente, e, quanto mais cansados estão os professores, senso comum, acredita-se que mais produziram conhecimento, pois este "produto" não é medível senão pelas manifestações tornadas concretas, por "provas" culturamente estabelecidas como "provas" de produção do conhecimento: avaliações, discursos, elaboração de material, concursos, avaliações externas. Obviamente, segmentando e exigindo melhor aproveitamento tempo, acaba-se por intensificar ${ }^{\mathrm{ix}} \mathrm{o}$ trabalho dos professores, reproduzindo a lógica do capital.

Neste sentido, reproduzindo o sistema capitalista, para o qual o tempo desenvolvese linearmente, enquanto se sabe, o tempo é dialético, ou como diz Bensaïd: "as formas do passado, do presente e do futuro acham-se na singularidade do agora" (1999, p.106), o trabalho acontece. Um tempo relacionado ao trabalho, medindo este na perspectiva de garantir o movimento do capital:

Dadas a intensidade e a produtividade do trabalho, o tempo que a 
sociedade tem de empregar na produção material será tanto menor e, em conseqüência, tanto maior o tempo conquistado para a atividade livre, espiritual e social dos indivíduos, quanto mais eqüitativamente se distribua o trabalho entre todos os membros aptos da sociedade, e quanto menos uma camada social possa furtar-se à necessidade natural do trabalho, transferindo-a para outra classe. Então, a redução da jornada de trabalho encontra seu último limite na generalização do trabalho. $\mathrm{Na}$ sociedade capitalista, consegue-se tempo livre para uma classe, transformando a vida inteira das massas em tempo de trabalho. (MARX, 2008, p. 607)

Em complemento, ao criticar o tempo na perspectiva do capitalismo, Bensaïd afirma: "O capital é uma organização conceitual específica e contraditória do tempo social" (1999, p. 113). O capital determina o tempo, como um meio de controle da produção. Porém,

[...] o eterno presente do capital, com seu 'tempo gelado de vitrine' não pode em absoluto varrer a aspiração da humanidade pelo estabelecimento de uma ordem social historicamente sustentável enquanto houver opressão e exploração no mundo. (MÈSZÀROS, 2007, p. 25)

Efeitos da lógica do capital aplicada ao trabalho dos professores, a intensificação, precarização e fragmentação inserem-se no modelo de flexibilização do trabalho, próprio do toyotismo que substituirá o modelo taylorista-fordista e será influente na organização da escola. Antunes contribui, afirmando: "O processo de produção de tipo toyotista por meio dos team work, supõe portanto uma intensificação da exploração do trabalho [...]" (2005, p. 56), tanto pelos trabalhadores ativarem e controlarem várias tecnologias diferenciadas, quanto pelo ritmo, pela agilidade para manter ativa e produtiva a maquinaria, resultando, finalmente, na quantidade e qualidade de produtos exigidos pelo sistema. (ANTUNES, 2005, p. 56) Os trabalhadores, entre eles, os professores, inseridos nessa lógica, têm a sensação contínua de não poderem gerenciar seu tempo, pois estão a serviço do capital, sob condições de gerenciamento da ação, sem, muitas vezes, perceberem que acabam por realizar seu trabalho automaticamente, ignorando, deste modo, ser o tempo a controlá-los e não são eles que controlam o tempo. Cabe também o alerta de Dejours que o limite do trabalho não se restringe somente ao tempo físico vivenciado no local de trabalho "[...] $\mathrm{O}$ trabalho ultrapassa qualquer limite dispensado ao tempo de trabalho; ele mobiliza a personalidade por completo". (DEJOURS, 2004, p. 30) Assim, tomados pela lógica implementada pelo capital ao seu trabalho, os professores, podem estar, contrariamente ao que pensam e ao que desejam, acreditarem estarem trabalhando, quando somente vivenciam uma situação de não-trabalho.

\section{O tempo como gerador do não-trabalho dos professores}

O trabalho dos professores acontece na linguagem, com a linguagem e através da linguagem. Nesse sentido, é um trabalho criativo por excelência, pois a produção da linguagem é uma ação social, entre sujeitos com diferentes culturas que, ao conviverem, vão se autoproduzindo também por meio da linguagem. Por isso, não há como entender o trabalho dos professores submetido absolutamente ao tempo, controlado por ele e sem 
momentos de fruição. O tempo para o trabalho dos professores precisa ser o que Mèszàros denomina de "tempo disponível":

[...] virtualmente ilimitado - porque generosamente renovável e ampliável - dos indivíduos sociais, capaz de ser colocado em uso criativo por eles como indivíduos auto-realizadores, contanto que os propósitos significativos a que suas ações servem emerjam de suas próprias deliberações autônomas. (MĖSZÀROS, 2007, p. 53)

Somente em condições de tempo assim o trabalho dos professores é trabalho, pois "Essa é a única maneira de transformar os potenciais emancipatórios da humanidade na realidade libertadora da vida cotidiana" (MÈSZÀROS, 2007, p. 53). Do contrário, em um tempo excessivamente regulado e limitador, há um não-trabalho dos professores. Passo a explicitar.

Se o trabalho é produção e autoprodução, o não-trabalho é reprodução. Se o trabalho é possibilidade de os sujeitos contribuírem com o social, o não-trabalho é a mera aceitação da condição de empregado, de funcionários do Estado, uma condição utilizada para se justificarem, e manterem-se empregados, temendo, por vezes, o enfrentamento de um desemprego. Nesse processo, o tempo é fatal.

\begin{abstract}
Porque o trabalho intelectual é contraditório com a lógica do capital. O seu tempo não pode ser enquadrado no tempo do processo de trabalho capitalista. O tempo do trabalho intelectual transborda o processo de trabalho capitalista, tal como ele se efetiva nas unidades industriais, agrícolas, comerciais e de serviços. [...] Simplesmente porque as idéias e as intuições invadem todo o tempo concentrado no trabalho intelectual. Como remunerar esse tempo? Qual o valor desse trabalho? (BEZERRA; SILVA, 2006, p. 6)
\end{abstract}

Cabe explicar que trabalho e emprego são diferentes. O trabalho está relacionado teleologicamente ao que é o ser humano, sua capacidade de intervir na natureza e de se constituir cidadão. $\mathrm{O}$ emprego diz respeito à capacidade dos seres humanos de manteremse, de poderem consumir. Para Organista, o emprego é uma categoria "[...] objetivada e mediatizada por relações contratuais jurídicas, historicamente demarcada e com forte aporte valorativo no imaginário popular" (ORGANISTA, 2006, p. 54), já o trabalho é mais abrangente, e não "[...] se restringe apenas aos processos considerados econômicos sctrito sensu (ORGANISTA, 2006, p. 54). O trabalho estabelece a condição de o mundo humano existir, o emprego reproduz as relações sociais, viabilizando as condições materiais de sobrevivência, mediante a venda da força de trabalho e um salário. Por isto, a categoria trabalho expressa algo que é mais amplo: "O trabalho funda o mundo dos homens [...]". Ou seja, o trabalho cria algo para além dos ser humano, algo diferente do ser que produz, “[...] remete para além de si próprio. É esse 'remeter para além de si próprió que faz do trabalho uma categoria única do ser social, sua categoria fundante [...] (SILVA JUNIOR; GONZALEZ, 2001, p. 13)

Segundo Engels, em texto descrevendo como o trabalho transformou os macacos em seres humanos, o trabalho não é somente a forma de acumular riquezas, mas constituise no modo de garantir a vida humana, possibilitando-o afirmar que "[...] o trabalho criou o próprio homem". (2004, p. 13) Nessa gênese, o autor destaca ter sido primeiro o trabalho e 
depois a linguagem os fatores de desenvolvimento passando os macacos à condição de seres humanos. Especificamente quanto ao trabalho, Engels afirma que, enquanto os animais apenas transformam a natureza por nela viverem, o ser humano, “[...] modifica a natureza e a obriga a servir-lhe, domina-a" (ENGELS, 2004, p. 18).

Um dos indicadores do tempo que realiza o emprego é a demasiada preocupação com o cumprimento de prazos, em detrimento do viver o tempo. Para Zarifian (2002), pode-se descrever essa relação social estabelecida com o tempo de prazos como sendo um tempo espacializado, que "[...] permanece em si mesmo sempre desprovido de sentido, desprovido de valor ético" (ZARIFIAN, 2002, p. 13). Não há fruição, há mecanização de movimentos, e o trabalho "Permanece uma pura relação calculada entre dois movimentos, o puro sustentáculo de uma computação de tempo econômico, mas dotado de funções sociais de grande utilidade" (ZARIFIAN, 2002, p. 13).

E, sobretudo na escola, o tempo pode ser restritivo. Iludidos pelo mundo capitalista, os professores envidam esforços ímpares para concretizar sua tarefa, subtraindo quaisquer diferenças, excluindo os desiguais e preenchendo infindos relatórios que mostrem, com evidências estatísticas, que o tempo considerado necessário para a produção do conhecimento foi aproveitado e, mesmo assim, o estudante não produziu conhecimento.

O trabalho dos professores é coordenar o tempo de produção de conhecimento, um trabalho árduo se continuar a se entender o tempo como linear. Por isso, melhor seria entendê-lo como sendo "[...] simultaneamente, institucional e pessoal, cultural e individual" (VIÑAO FRAGO, 1998, p. 5). Institucional porque previsto e uniforme; pessoal, porque diversificado, e "[...] Não existe apenas um tempo, mas uma variedade de tempos: no mínimo, o do professor e o do aluno. Mas também o da administração, o da inspeção, o tempo regrado" (VIÑAO FRAGO, 1998, p. 5). Além disso, sendo tempo cultural, na escola, é uma "[...] construção social historicamente cambiante, um produto cultural que implica uma determinada vivência ou experiência temporal" (VIÑAO FRAGO, 1998, p. 5). Portanto, é um tempo elaborado social, cultural e pedagogicamente (por isso, politicamente), simultaneamente, vivenciado "[...] não apenas pelos professores e pelos alunos, mas também pelas famílias e pela comunidade em seu conjunto, mediante sua inserção e relações com os demais ritmos e tempos sociais". (VIÑAO FRAGO, 1998, p. 5)

Nesse espaço e nesse tempo, acontece o trabalho dos professores que denomino pedagógico, porque entendo ser uma ação em relação ao conhecimento. Para produzir seu trabalho pedagógico, os professores organizam tempos em aula, mas há também os tempos extraclasse: "Momentos que acontecem, normalmente, fora da jornada de trabalho da laboralidade pedagógica, distante do controle do capital" (BEZERRA; SILVA, 2006, p. 6). Esses também são momentos de trabalho dos professores, de planejamento, avaliação, criação: "O trabalho pedagógico tem, imanente a si, momentos de plena liberdade que nenhuma forma de trabalho possui. São momentos do pensar concentrado, quando tomamos consciência daquilo que queremos conhecer". (BEZERRA; SILVA, 2006, p. 6) Portanto, o trabalho dos professores exige tempos múltiplos, na escola e para além da espacialização escolar, não podendo ser medido pela temporalidade instituída na escola. Além disso, reitero que o tempo de trabalho dos professores, para garantir que haja a produção do conhecimento efetiva, tanto sua quanto dos estudantes, precisa ser descolado da lógica do capital, permitindo-lhes agir e criar. E os autores consideram, também, ser o tempo dedicado ao trabalho pedagógico, propício para a multiplicação das possibilidades de criação, não sendo possível controlá-lo, porque "[...] Esse é realmente o tempo de criatividade intelectual mais intenso. Conseqüentemente, a racionalidade do capital não pode penetrar nesse tempo". (BEZERRA; SILVA, 2006, p. 6) 
Com base em todas essas considerações, acredito que a superação do estágio de ser mão-de-obra a serviço do capital e o reencontro com a efetiva produção do trabalho pedagógico, ou seja, a "desautomatização" dos professores iniciará quando lhe for permitido que expresse sua capacidade de planejar, coordenar e produzir conhecimento, ou seja, realizar seu trabalho pedagógico. Ou seja, que recuperem o gosto por pensar e vivenciar o seu trabalho como professores, lembrando que "[...] o tempo do cotidiano compartilhado é um tempo plural, o tempo dentro do tempo". (SANTOS, 1994, p. 17)

\section{Considerações a tempo de fechar o texto.}

Pretendeu-se iniciar uma discussão que necessita continuar. O tempo, essa criação cultural humana, com o intuito de possibilitar acompanhar-se a existência, entendê-la, e, ao mesmo tempo, regulá-la, pode se tornar, na escola, um elemento de impedimento ou prejuízo ao trabalho dos professores, seja porque extremamente regulada impede a produção do conhecimento, seja porque negligenciada produz o mesmo efeito, gerando o que denomino não-trabalho, no sentido explicitado anteriormente. Assim, um entendimento de como acontece a relação entre os professores o tempo e o espaço - estes entendidos indissociadamente - possibilita que se teçam considerações contributivas para o trabalho de produção do conhecimento, para a aula, para a escola. Talvez começando por desmistificar o tempo: não o tempo da circularidade, sob a face contemporânea da rotina ou o criado pelos povos antigos, nem um tempo de relações metafísicas entre sujeitos, movimento e universo; tampouco o tempo medievo regulado pelas leis divinas ou pela razão moderna. Um tempo e um espaço que os sujeitos precisam compreender para produzir, pois, a não ser por mera reprodução de algo, senso comum, denominado rotina, não há nada que impeça a escola de ser um movimento de resistência tanto às lógicas do capital quanto às imposições sociais desumanizadoras, geradas pelo avanço das tendências neoliberais. Ao contrário, o local ainda é um espaço de resistência e o tempo pode ser seu principal artifício. Evitar que o tempo traia a si próprio pode significar reconstituir as condições de a produção do conhecimento, e contribuir para o trabalho dos professores na escola, acontecer.

\section{REFERÊNCIAS}

ANTUNES, R. Os sentidos do trabalho: ensaio sobre a afirmação e a negação do trabalho. São Paulo: Boitempo editorial, 2005.

APPLE, M. W; JUNGCK, S. "No hay que ser maestro para enseñar esta unidad: la ensenanza, la tecnología y el control en el aula". Revista de Educación, n. 291, p. 149-172, 1990.

BENSAÏD, D. Marx, o intempestivo: grandezas e misérias de uma aventura crítica. Rio de Janeiro: Civilização Brasileira, 1999.

BEZERRA, C. "Mercadorização e precarização do trabalho docente: contradições entre prática pedagógica e trabalho pedagógico". In: VI Seminário da REDESTRADO, nov.2006. RJ, p. 1-15

BOSI, A. (org.) Cultura brasileira: temas e situações. SP: Ática, 1987.

CHAUÍ, M. Brasil - Mito fundador e sociedade autoritária. São Paulo, Perseu Abramo, 2000.

CONTRERAS, J. Autonomia de professores. SP: Cortez, 2002. 
DEJOURS, C. "Subjetividade, trabalho e ação". In: Revista Produção, v. 14, n. 3, p. 027-034, Set./Dez. 2004.

ENGELS, F. "Sobre o papel do trabalho na transformação do macaco em homem". In: ANTUNES, R. (Org.) A dialética do trabalho. São Paulo: Expressão Popular, 2004.

ENGUITA, M. A face oculta da escola: educação e trabalho no capitalismo. Porto Alegre: ARTMED, 1989.

ESCOLANO, A. "Arquitetura como programa: espaço-escola e currículo". In: FRAGO, A.V.; ESCOLANO, A. Currículo, espaço, subjetividade: a arquitetura como programa. Rio de Janeiro: DP\&A, 1998.

GOERGEN, P. "Espaço e tempo na escola: constatações e expectativas". IN: www.cori.unicamp.br/foruns/magis/evento5/Texto\%20PEDRO.doc (Acesso em 17 de abril de 2009)

GOUREVITCH, A. Y. "O tempo como problema histórico cultural". IN: As culturas e o tempo estudos reunidos pela UNESCO. SP: UNESP, 1975.

HAWKING, S. Breve História do tempo. 3ª Ed. Lisboa: Gradiva,1994.

HARGREAVES, A. Os professores em tempos de mudança: o trabalho e a cultura dos professores na idade pós-moderna. Portugal: Mc Graw-Hill, 1998.

JULIEN, F. Tratado da eficácia. São Paulo: Editora 39, 1998.

LANER, A. S. Psicologia e trabalho na História. Ijuí: Editora UNIJUI, 2005.

LE GOFF, Jacques. Para um novo conceito de Idade Média: tempo, trabalho e cultura no ocidente. Lisboa: Editorial Estampa, 1979.

MARX, K. Salário, preço e lucro. In: CIVITA, V. (Ed.) Os pensadores: Karl Marx. São Paulo: Abril Cultural, 1974, p.63-105.

MARX, K. O capital. crítica da economia política. Vol.1. Livro Primeiro: O processo de produção do capital. Tomo I. Rio de Janeiro: Civilização Brasileira, 2008.

MÉSZÁROS, I. A educação para além do capital. São Paulo: Boitempo, 2005.

MÈSZÀROS, I. O desafio e o fardo do tempo histórico. SP: Boitempo, 2007.

NORONHA, O. M. "Quanto tempo o tempo tem!" In: Educação \& Sociedade, v.24, n.85, Campinas, dez. 2003

NUNES, B. "Experiências do tempo". In: NOVAES, A (Org.). Tempo e história. SP: Companhia das Letras, 1992. pp. 131-140.

ORGANISTA, J.H.C. O debate sobre a centralidade do trabalho. São Paulo: Editora Expressão Popular, 2006.

PRIGOGINE, Y. "O papel criativo do tempo". IN: O nascimento do tempo. Lisboa, Edições 70, 2008. 
SANTOS, M. Técnica, espaço, tempo - globalização e meio técnico-científico informacional. SP: Hucitec, 1994.

SILVA JUNIOR; GONZÁLEZ, J. C. Formação e trabalho: uma abordagem ontológica da sociabilidade. São Paulo, SP: Xamã, 2001.

TAYLOR, F. W. Princípios da Administração Científica. 8. ed. São Paulo: Atlas, 1990.

TASSINARI, a. "Einstein e a modernidade". In: Novos Estudos - CEBRAP, n. 75, v. 58, São Paulo, julho, 2006. pp. 157-170.

THOMPSON, E. P. "O tempo, a disciplina do trabalho e o capitalismo". IN: SILVA, T. T. da. (org.). Trabalho, Educação e Prática Social - Por uma teoria da formação humana. Porto Alegre: Artes Médicas, 1991.

VIÑAO FRAGO, A. Tiempos escolares, tiempos sociales. Barcelona: Editorial Ariel Practicum, 1998.

WHITROW, G. J. O tempo na História: concepções de tempo da pré-história aos nossos tempos". RJ: Jorge Zahar, 1993.

ZARIFIAN, P. "O tempo do trabalho: o tempo-devir frente ao tempo espacializado". USP: Tempo Social; vol. 16, 2002, pp.1-18.

Recebido dia 10/02/2010

Avaliado dia 19/02/2010

\footnotetext{
${ }^{\text {i }}$ Sendo pedagógico é essencialmente político, porque exige a participação cidadã nas condições históricas, sociais, políticas nas quais a educação, a escola, o conhecimento, os professores estão imersos, compreendendo-as, agindo em lutas em prol de transformações nas condições de trabalho.

ii Produção do conhecimento no sentido de apropriação individual de algo que não sabia, por meio de processos afetivos, cognitivos próprios, embora em contextos de interação e linguagem com outros sujeitos e com o mundo.

iii Para fins desse trabalho, utilizo a expressão "não-trabalho" como sendo a não ocorrência do trabalho, a não-produção, a ser explicitada na seqüência.

${ }^{\text {iv }}$ Considero mito uma narrativa e concordo com importante destaque apresentado por Chauí: "Ao falarmos em mito, nós o tomamos não apenas no sentido etimológico de narração pública de feitos lendários da comunidade (isto é, no sentido grego da palavra mythos), mas também no sentido antropológico, no qual essa narrativa é a solução imaginária para tensões, conflitos e contradições que não encontram caminhos para serem resolvidos no nível da realidade". (2000)

v Narrar é um modo de organizar os feitos em um tempo, tanto real quanto psicológico e, sem essa sequenciação temporal, a narrativa fica incompleta. Ao narrador, cabe estabelecer essa temporalidade, organizando os fatos para que se façam entendíveis.
} 


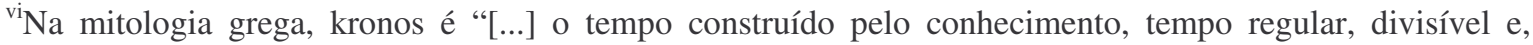
portanto, controlável", o aspecto quantitativo do tempo" (JULIEN, 1998, p. 92); já o Kairós, é um tempo com maior qualidade e oportunidade: "o tempo aberto à ação e constituído pela ocasião, tempo perigoso, caótico e, portanto, indomável” (JULIEN, 1998, p. 92).

vii Para uma melhor compreensão do que seja capital, cito Mèszàros, para quem o capital não é uma entidade somente material: "Não é possível pensar em nenhum aspecto de nossa vida que não seja, nesse sentido, controlado pelo capital sob as circunstâncias presentes" (MÈSZÀROS, 2007, p 68). Com base em Mèszàros, 2005 e Antunes, 2005, penso que capital e capitalismo são diferenciados e o que coordena as relações sociais na contemporaneidade é o capital.

viii Emprego e trabalho são diferentes. Este é possível sem aquele. O emprego é, assim, a condição formal do trabalho, mediante um contrato de venda da força de trabalho. Portanto, trabalha-se sem emprego, e pode-se estar empregado e não produzir, gerando o não-trabalho no sentido que se utiliza neste artigo.

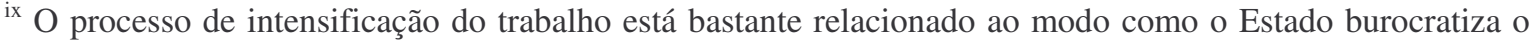
trabalho, cria um planejamento e uma forma de controle externos ao trabalho. Com isso, "[...] favorece a rotinização do trabalho, já que impede o exercício reflexivo, empurrado pela pressão do tempo" (CONTRERAS, 2002, p. 37). Tais processos contribuem para a elaboração de modos de vida cada vez mais desgastantes, buscando corresponder às inúmeras tarefas cotidianamente atribuídas. Para Apple e Jungck, a intensificação torna o trabalho apressado, exige o controle e o apoio de especialistas, procurando garantir quantidade de produção, de modo que "o 'trabalho feito' se transforma no substituto do 'trabalho bem-feito" (APPLE; JUNGCK, 1990)
} 